\title{
Passive Sampling of Ambient Nitrogen Dioxide Using Local Tubes
}

\author{
Rejina Maskey Byanju ${ }^{1,2^{*}}$, Mohan Bikram Gewali ${ }^{2}$, Krishna Manandhar ${ }^{2}$ \\ ${ }^{1}$ Central Department of Environmental Science, Tribhuvan University, Kathmandu, Nepal; ${ }^{2}$ Central Department of Chemistry, Trib- \\ huvan University, Kathmandu, Nepal. \\ Email: *merejina@yahoo.com,rmaskey@cdes.edu.np
}

Received December 1 $1^{\text {st }}, 2011$; revised January $1^{\text {st }}, 2012$; accepted February $2^{\text {nd }}, 2012$

\begin{abstract}
Traditional active and automated sampling of nitrogen dioxide $\left(\mathrm{NO}_{2}\right)$ monitoring techniques require expensive instrumentation which is not easily adapted for large scale monitoring by resource limited countries. This paper presents the use of locally available relatively cheaper polyethylene tubes to be developed as passive diffusive sampler and use for monitoring of ambient nitrogen dioxide using Triethanolamine (TEA) as absorbent. After extraction with double distilled water, modified Griese-Saltzmann method is used for analysis of nitrite adduct formed due to reaction of $\mathrm{NO}_{2}$ with TEA using spectrophotometer. The results are compared with Ferm-Badge type passive samplers from IVL-Sweden and high volume sampling methods. The detection limits of the passive sampling methods were found to be suitable to be use in tested environment and precision of the method as expressed as Coefficient of variation are good enough for monitoring of $\mathrm{NO}_{2}$ in ambient air of Kathmandu. The method shows strong correlation with high volume sampler and no significant difference with Ferm-Badge-IVL samplers at $\mathrm{p}=0.05$.
\end{abstract}

Keywords: Nitrogen Dioxide; Passive Sampler; Diffusive Sampling

\section{Introduction}

Nitrogen dioxide $\left(\mathrm{NO}_{2}\right)$ is one of the ubiquitous pollutants found in the ambient air which exhibit documented adverse effects on health and welfare [1]. While standard $\mathrm{NO}_{2}$ monitoring techniques require expensive instrumentation, diffusive samplers, also called passive samplers, are light weight, inexpensive and do not need maintenance, on-site power and pumping [1,2].

Therefore passive samplers which offer a simple, costeffective means of measuring air pollutants have been performed for the monitoring of ambient $\mathrm{NO}_{2}$ level worldwide [3-5]. The simplest diffusion sampler is the tube-type sampler first introduced by Palmes et al. [2] These earlier tubes use triethanolamine (TEA) as absorber. With the time several different types of passive samplers been developed using different absorbers. Noticeably, at present at least five reasonably well developed passive sampling methods for determination of $\mathrm{NO}_{2}$ is in use. They are Palmes tube; the Yanagisawa and Nishimura method, [6] the modified Amaya-Sugira method [7-10]; the Cadoff and Hodgeson method [11]; the Lewis and Mulik method [12], and the Ferm method [13].

Passive samplers are generally designed either in a tubetype configuration with one end open (so-called "Palmes ${ }^{*}$ Corresponding author. tubes"); or in a shorter badge-type configuration, where the open end is protected by a membrane filter or other wind screen. In either case, the closed end contains an absorber for the gaseous species to be monitored. Several different types of commercial diffusion tubes are there in market in recent time. These includes: Ivl-Sweden, Gradko, UK; Rediolle, Italy; Ogawa, Japan etc. All of these samplers were developed basically from above mentioned two types of diffusion tubes and available in the different cost rate according to manufacturer. For example, Gradko tubes cost $\$ 10$ per sampler while Rediolle from Italy cost Euro 30 per sampler. Thus, these commercially available passive samplers are still costly for a developing country like Nepal. Hence it is in pertinent to have a sampler which is affordable and logistically feasible to be sampled and analyzed in our environment. In this line we describe here such an attempt to use locally available polyethylene tubes with triethanolamine coated filter paper to be used as $\mathrm{NO}_{2}$ sampler and ambient monitoring of the same.

\section{Operating principle of Passive samplers}

The basic principle on which diffusion tube samplers operate is that of molecular diffusion, with molecules of a gas diffusing from a region of high concentration (open end of the sampler) to a region of low concentration (absorber end of the sampler). The movement of molecules 
of gas (1) through gas (2) is governed by Fick's law, which states that the flux is proportional to the concentration gradient:

$$
\mathrm{J}=\mathrm{D}_{12} \mathrm{dc} / \mathrm{dz}
$$

where, $J=$ the flux of gas (1) through gas (2) across unit area in the $\mathrm{z}$ direction $\left(\mu \mathrm{g} \cdot \mathrm{m}^{-2} \cdot \mathrm{s}^{-1}\right)$;

$\mathrm{c}=$ the ambient ozone concentration $\left(\mu \mathrm{g} \cdot \mathrm{m}^{-3}\right)$;

$\mathrm{z}=$ the length of the diffusion path $(\mathrm{m})$;

$\mathrm{D}_{12}=$ the molecular diffusion coefficient of gas (1) in gas (2) $\left(\mathrm{m}^{2} \cdot \mathrm{s}^{-1}\right)$.

For a cylinder of cross-sectional area a $\left(\mathrm{m}^{2}\right)$ and length $\mathrm{L}(\mathrm{m})$ then $\mathrm{Q}(\mu \mathrm{g})$, the quantity of gas transferred along the tube in $\mathrm{t}$ seconds (taken as the quantity of gas absorbed during $\mathrm{t}$ ) is given by:

$$
\mathrm{Q}=\mathrm{D}_{12}\left(\mathrm{C}_{1}-\mathrm{C}_{0}\right) \text { at } / \mathrm{L}
$$

where, $\mathrm{C}_{0}$ and $\mathrm{C}_{1}$ and are the gas concentrations at either end of the tube.

In a diffusion tube, the concentration of gas (1) is maintained at zero by an efficient absorber at one end of the tube (i.e. $\mathrm{C}_{0}$ is zero) and the concentration $\mathrm{C}_{1}$ is the average concentration of the gas (1) at the open end of the tube over the period of exposure. Hence:

$$
\mathrm{C}=\mathrm{Q}_{1} / \mathrm{D}_{12} \text { at }
$$

The diffusion coefficient for the gas to be monitored must be determined, or obtained from the literature. The area and length of the tube are determined by measurement.

The sampling rate (SR) of passive samplers can be calculated using the formula:

$$
\mathrm{SR}=\mathrm{D}_{12} \mathrm{a} / \mathrm{L}
$$

Then they were expressed as $\mathrm{ml}$ of air sampled per second. This makes it possible to compare directly sampling rates of passive samplers with those of active samplers $[14,15]$.

\section{Materials and Method}

\subsection{Description of the Study Area}

Kathmandu Valley - the capital of Nepal is located between $27^{\circ} 37^{\prime} 30^{\prime \prime} \mathrm{N}$ and $27^{\circ} 45^{\prime} 0^{\prime \prime} \mathrm{N}$ latitude and $85^{\circ} 15^{\prime} 0^{\prime \prime} \mathrm{E}$ and $85^{\circ} 22^{\prime} 30^{\prime \prime} \mathrm{E}$ longitude. It lies between the Himalayas in the North and the Mahabharata range in the South. The valley lies at an altitude of $1300 \mathrm{~m} \cdot \mathrm{msl}$ and is surrounded by a high mountain range (above $2000 \mathrm{~m}$ ). The valley has a sub-tropical, temperate climate. The valley receives $80 \%$ of its annual rainfall during the summer monsoon i.e. June through mid-September. The ambient air temperature may increase up to $35^{\circ} \mathrm{C}$ during hot summer days and may decrease up to $-1^{\circ} \mathrm{C}$ during cold winter months [16]. The relative humidity reaches more than $80 \%$ during the rainy season but decreases to less than
$50 \%$ during the dry season. The major part of the winds blowing in the valley is southwesterly [17]. Wind speed lies in the range of $0.5-7.5 \mathrm{~m} / \mathrm{s}$.

In recent years, due to migration and urbanization accompanied by increase in population, vehicles and industries, air pollution became a known environmental problem posing a threat to health and well being among the inhabitants especially in its urban centers. Kathmandu valley, is one of the major urban centers of the country, facing such a problem of air pollution $[18,19]$. The level of atmospheric pollution in the city has in close been compared to that of other industrialized city of the Asia such as Calcutta, Bombay, Delhi, Sanghai etc. [20]. Transport sector is one of the major contributors of air pollution in Kathmandu. Due to its typical bowl shaped topography, restricting wind movement together with anthropogenic activities, $\mathrm{NO}_{2}$ along with other major pollutants such as $\mathrm{SO}_{2}, \mathrm{TSP}, \mathrm{PM}_{10}, \mathrm{PM}_{2.5}, \mathrm{CO}, \mathrm{CO}_{2}$ are in increasing trend.

With the establishment of six Ambient Air Quality Monitoring stations at different locations of Kathmandu valley in 2002, under MOPE (then Ministry of Population and Environment now MOEST, Ministry of Environment) started to gather the air pollution data. Since then TSP, PM10, $\mathrm{NO}_{2}, \mathrm{SO}_{2}, \mathrm{CO}$, Benzene has being monitoring. The National threshold limits for these pollutants also being set up. According to the latest monitoring result TSP, $\mathrm{PM}_{10}$ and $\mathrm{PM}_{2.5}$ has been exceeded the NAAQS value except in monsoon season while $\mathrm{NO}_{2}$, $\mathrm{SO}_{2}, \mathrm{CO}, \mathrm{HCs}$ are in higher for roadside stations than the NAAQS for the Kathmandu valley [21]. However, due to power failure and other constraints these monitoring stations are continuously disturbed. Furthermore, the monitoring data are not yet been precisely used in assessment and air quality management planning within the country.

\subsection{Methods}

\subsubsection{Diffusion Sampler Preparation}

Polyethylene tubes of $5 \mathrm{~cm}$ long with $1.2 \mathrm{~cm}$ cross $\mathrm{sec}-$ tion with one end open from local supplier were used for sampling. Filter paper (GF/A) cut into the circular equal to the inner cross section of the tube dipped into double distilled (dd) water for $24 \mathrm{hr}$ followed by air drying was placed into the closed end of the tube. TEA water was fed in each diffusion tube as trapping solution on GF/A filter paper used as absorbent base.

\subsubsection{Exposure of Diffusion Tubes}

Two sets of campaign exposures and analysis were done one for rainy season (July-October, 2007) and other dry season (February-April, 2008), according to the pattern of pollution scenario observed in the valley predicted from the previous monitoring results [21,22]. Samples were 
exposed at five sites in the first exposure and three additional sites were used for second exposure. Figure 1 and Table 1 show the information about the sampling sites.

Except site one, at the rest of the sites diffusive samplers from IVL, Sweden were co exposed. IVL, diffusive samplers for several gases have been developed and described in the literature $[3,5,23]$. The IVL samplers are of badge type, $10 \mathrm{~mm}$ long and $20 \mathrm{~mm}$ internal diameter. A membrane is mounted at the inlet to prevent them from wind-induced turbulent diffusion. The membrane is protected from mechanical damage by a stainless steel mesh. The samplers are normally mounted under a metal disc (rain shield) attached to an aluminum arm. The measuring range for $\mathrm{NO}_{2}$ (bi-monthly sampling is about 0.05 to $50 \mu \mathrm{g} \cdot \mathrm{m}^{-3}$. The $\mathrm{NO}_{2}$ samplers have been compared to active sampling within a routine network have been described in literature [3]. These samplers have been used for the measure of $\mathrm{NO}_{2}$ and other gases in Asia, Africa and South America as well [24]. The IVL samplers were mailed back to IVL, Sweden where they were analyzed using ion chromatography.

At site one active sampling for $\mathrm{NO}_{2}$ was carried out using High Volume sampler from Enviro tech, during the exposure of developed diffusive tube.

Total of 60 samplers were exposed at five sites on first exposure for four weeks on October, 07 to November, 07. Second exposure (dry season) was carried out during February-March, 2008 with the improvement in sampler preparation based upon the result from first exposure analysis.
Total of 104 samplers were exposed in second campaign.

Recommendations from previous researches had been considered for the exposures such as, Installation of blanks, storage of samplers in a refrigerator [25]. The samplers were exposed in vertically inverted position with the open end downwards inside shields to protect them from wind, sunlight, rain, and draught [26-28]. Plastic boxes were fixed with net as shield for diffusion tube sampler holder for exposure (Figure 2).

\subsubsection{Sample Extraction and Analysis}

To the diffusion tubes collected after exposure of prescribed time period weeks, $\mathrm{NO}_{2}$ was extracted adding 1 $\mathrm{ml}$ of double distilled (dd) water. The tube was left for 15 minutes for extraction of all the $\mathrm{NO}_{2}^{-}$present on the filter paper, and the tube was closed. Standard nitrite solution and Extracted samples were analyzed for nitrite using Modified Griess-Saltzman method spectrophotometrically at $540 \mathrm{~nm}[2,14,12,15]$.

All the chemicals used were of analytic grade.

\subsection{Comparison between Absorbents}

\subsection{1. $20 \%, 30 \%$ and $50 \%$ v/v Aqueous TEA}

Five sets of triplicates of three different absorbent concentrations; $20 \%$ v/v TEA- $\mathrm{H}_{2} \mathrm{O} ; 30 \%$ TEA- $\mathrm{H}_{2} \mathrm{O}$ and $50 \%$ TEA- $\mathrm{H}_{2} \mathrm{O}$, using $20 \mu \mathrm{l}$ diffusion tubes were prepared and were co-exposed randomly at different sites for two weeks and tested.

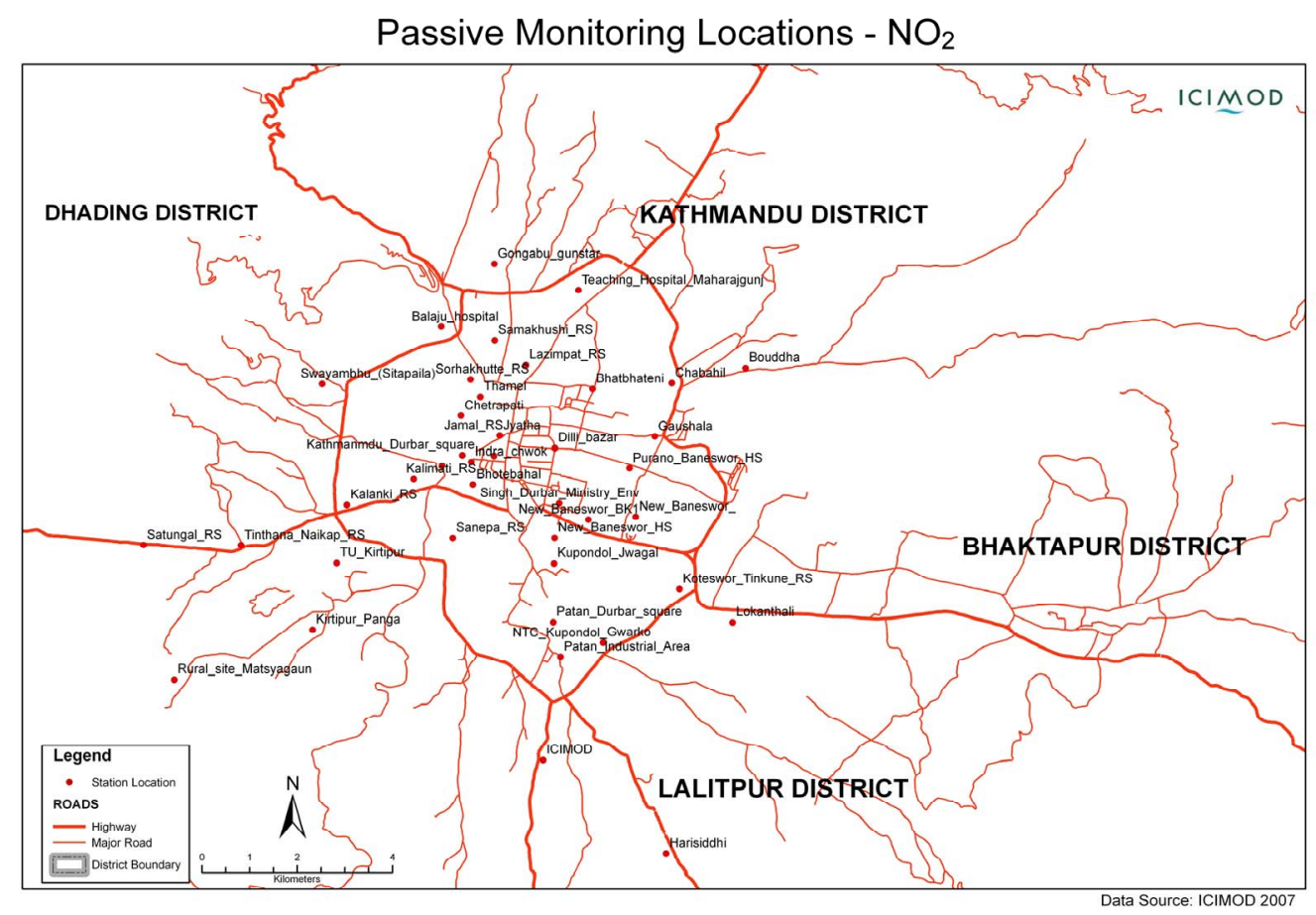

Figure 1. Diffusion tube exposure sites. 
Table 1. Description of sampling sites.

\begin{tabular}{ccccc}
\hline Exposure Station sites & Latitude $\left({ }^{\circ} \mathbf{N}\right)$ & Longitude $\left({ }^{\circ} \mathbf{E}\right)$ & Altitude $(\mathbf{m})$ & Remarks \\
\hline 1. Bijuli bazaar RS ${ }^{1}$ (Road side) & 27.6795 & 85.3245 & 1304 & High volume sampler sampling station \\
2. New Baneswor HS ${ }^{2}$ & 27.6885 & 85.3253 & 1311 & Road side + high slope \\
3. New Baneswor RS & 27.6925 & 85.3407 & 1316 & Intermediate site (Road side with less traffic) \\
4. Maitighar RS & 27.6934 & 85.3216 & 1304 & High traffic \\
5. Indra chwok RS & 27.7029 & 85.3096 & 1303 & Market center \\
6. Thamel, MOEST & 27.7152 & 85.3113 & 1321 & Urban Residential , Ministry's monitoring station \\
7. Kalimati RS & & 85.2987 & 1443 & High traffic road intersection \\
8. New Baneswor BK & & 27.6996 & 1310 & Inside residential area Urban Background site \\
\hline
\end{tabular}

Note: RS = Road side monitoring sites; BK = Back ground monitoring sites; HS = High slope road side monitoring sites; MOEST = Continuous monitoring stations of Ministry of Environment.

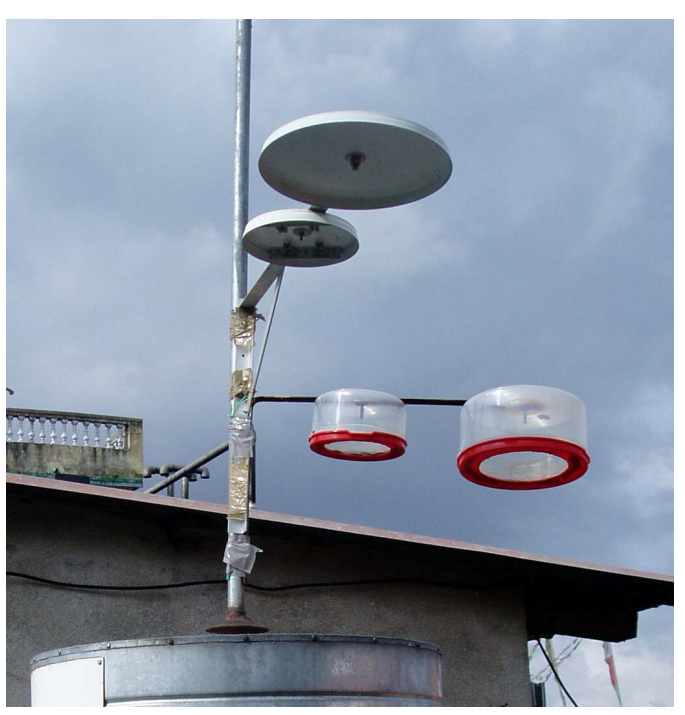

Figure 2. Co exposure of developed test diffusion tubes and Ferm-IVL sampler.

\subsubsection{Comparison between Absorbents Volumes}

Five sets of triplicates of two different volumes of $10 \mu 1$, and $30 \mu \mathrm{l}$ of $20 \%, 30 \%$ and $50 \% \mathrm{v} / \mathrm{v}$ aqueous TEA were tested for two weeks exposure.

\subsection{Statistical Analysis}

\subsubsection{Method Validation}

Precision was expressed as the coefficient of variation (CV), also referred to as relative precision by the US EPA, CV was calculated as the sample standard deviation divided by the sample mean times $100 \%$.

Accuracy of passive sampler was evaluated by comparing the measured results with the co-exposed FermBadge sampler from IVL Sweden, which was analyzed by standard ion chromatographic analysis at IVL. The results are also compared with the data from the active monitoring by high volume sampler using TEA as trapping agent followed by same procedure, the Modified Griess-Saltzman spectrophotometric method [2,11-13,29].
The active monitoring was performed during the test sampler exposure periods.

\subsubsection{Uncertainty Analysis}

Detection limit and minimum detectable quantity

For this research, two kinds of detection limit (DL) were calculated. The first DL was for the analytical equipment, spectrophotometer and second DL was for the entire sampling method of $\mathrm{NO}_{2}$ for different periods of exposure of tubes. The DL for the spectrophotometer was calculated from a calibration curve with the help of Equation (5) (Miller and Miller, 1984) [30]. The detection limit $(\mathrm{Y})$ is the analyte concentration that gives a signal equal to the blank signal (YB) plus three standard deviations of the blank, SB.

$$
\mathrm{Y}=\mathrm{YB}+3 \mathrm{SB}
$$

The detection limit for the passive sampling method was calculated by multiplying the standard deviation of blank values with one-tailed t-value (degrees of freedom at $99 \%$ confidence level). The equation is given below.

where,

$$
\mathrm{DL}=\mathrm{SB} \times \mathrm{t}_{(\mathrm{a}, \mathrm{n}-1)}
$$

$\mathrm{SB}=$ standard deviation of blank values

$\mathrm{t}_{(\mathrm{a}, \mathrm{n}-1)}=$ critical value of $\mathrm{t}$-distribution with $\mathrm{n}-1 \mathrm{de}-$ grees of freedom and a Significance level of á (0.01 levels).

\section{Results and Discussion}

This work presents an affordable cheap method to passively measure ambient $\mathrm{NO}_{2}$ and $\mathrm{SO}_{2}$ using locally available polyethylene tubes. Passive measurement includes development of these tubes into diffusive tubes using triethanolamine (TEA) as absorbent. Calibration curve from nitrite $\left(\mathrm{NO}_{2}^{-}\right)$standards were prepared and used for subsequent analysis of blanks and exposed tubes. Same standard curve was used for the calculation of detection limits as well.

Average value of $\mathrm{NO}_{2}$ from the exposed tubes after 
subtraction from that of the blanks at the corresponding sites was used in Equation (3) to determine $\mathrm{NO}_{2}$ concentration in $\mu \mathrm{g} / \mathrm{m}^{3}$ in ambient air. Diffusion coefficients for $\mathrm{NO}_{2}$ in ambient air used is $1.54 \times 10^{-5} \mathrm{~m}^{2} \cdot \mathrm{s}^{-1}[15]$.

Figure 3 presents the exposure measurement of $\mathrm{NO}_{2}$ concentration for field exposure. The result of all exposures provides a reliable ambient $\mathrm{NO}_{2}$ passive sampler with good precision, quite capable of comparison to the other methods. Precision of $\mathrm{NO}_{2}$ measurement for two week exposure period was found to be $21.4 \%$ compared adequately with the US National Institute of Safety and Health (NIOSH) acceptance criterion (25\%) for field performance of passive sampler applications in air [31]. In each station the concentration of $\mathrm{NO}_{2}$ were higher for second exposure period, as expected. The range of $\mathrm{NO}_{2}$ as measured was 0.8 to $15.3 \mu \mathrm{g} / \mathrm{m}^{3}$ for rainy season and 10.5 to $52.2 \mu \mathrm{g} / \mathrm{m}^{3}$ for dry season (Figure 3).

The number of samples collected was lower than the number of exposed tubes installed and analyzed. Some of the field blanks and the exposed tubes gave negative absorbance values. The filter papers dropped out from some of the tubes at site 1,4 and 5. The dropped out are more for $\mathrm{NaOH}$ plus $\mathrm{NaI}$ absorbent tubes. These vandalisms were reduced in second exposure.

Blank absorbances for unexposed tubes were found to be equivalent to a mean nitrite mass of $0.03 \mu \mathrm{g} / \mathrm{m}^{3}$ for preparation using aqueous TEA solution. The blank values present the status of preparation of diffusive sampling methods. Thus in this study the CV of blank tubes were found to be of $13.7 \%$ with standard error of the mean 0.0014 for $\mathrm{NO}_{2}$.

A repeated test for repeated measures of $\mathrm{NO}_{2}$ for two exposures implied significant difference for five sampling sites (Site 1 - 5) and also for 1st and second exposure periods. As mentioned earlier second exposures were carried out during month of February-March with the additional three more sites (Total of eight) sites 1 to 8 . The result shows the highest concentration of $\mathrm{NO}_{2}$ at the site 7 , Kalimati, which represents a road side with high traffic intensity. Site 8 is a residential urban background site showing lowest concentration of $\mathrm{NO}_{2}$. The result shows that vehicles could be the one of the major sources of $\mathrm{NO}_{2}$ in Kathmandu.

\subsection{Absorbent Test}

A study was conducted to compare between two absorbents for $\mathrm{NO}_{2}$. No significant difference was found between two kinds of absorbents used for $\mathrm{NO}_{2}$ (Table 2), still high percentage of drop out were observed for $\mathrm{NaOH}+\mathrm{NaI}$ as an absorbent for ambient air $\mathrm{NO}_{2}$ sampling. The losses of $\mathrm{NO}_{2}$ were observed by using TEA for long-term sampling [3]. $\mathrm{NO}_{2}^{-}$TEA adduct is prone to photo degradation while exposing the tubes in sun. ${ }^{1}$ Further work is required to find out the best absorbent for

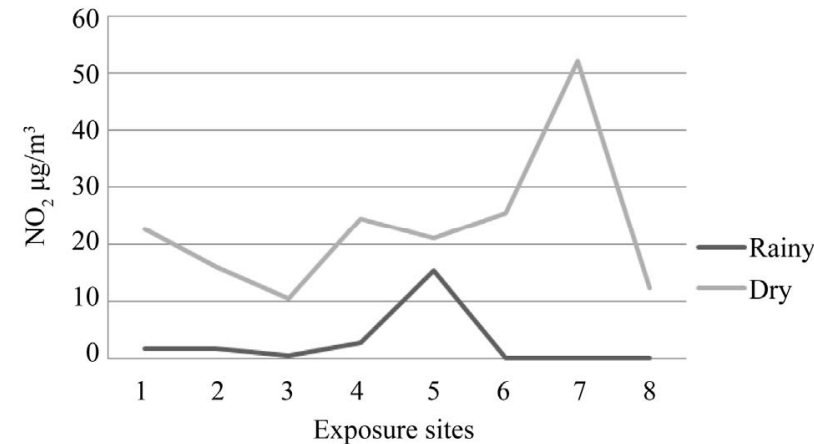

Figure 3. Field exposures result for ambient concentration of $\mathrm{NO}_{2}$.

Table 2. Results of $\mathrm{NO}_{2}\left(\mu \mathrm{g} / \mathrm{m}^{3}\right)$ from exposure analysis using TEA and NaOH plus NaI (July, 2007).

\begin{tabular}{ccc}
\hline Sampling site & Tube with TEA & Tube with NaOH plus NaI \\
\hline 2 & $3.99 \pm 0.62$ & $4.15 \pm 0.68$ \\
4 & $4.59 \pm 0.98$ & $4.15 \pm 0.38$ \\
5 & $17.52 \pm 17.00$ & $15.08 \pm 13.72$ \\
\hline
\end{tabular}

NB: No significance difference between absorbents at $\mathrm{p}<0.05$.

passive sampling of $\mathrm{NO}_{2}$ measurements.

Not only the type of absorbent but their volume and concentration also were the integral part of the passive sampling.

Five exposure sets were deployed to determine whether the aliquot volume used on the diffusion tube also contributed to differences in $\mathrm{NO}_{2}$ uptake by the samplers (Comparison of aliquot volume). Pair t-tests showed no difference between compared sampler means, indicating that $\mathrm{NO}_{2}$ uptake was equivalent for samplers prepared using aliquot volumes in the range $10-30 \mu \mathrm{l}$. However for the samplers with aliquot volume $10 \mu \mathrm{l}$, there was higher rate of drop out $(\approx 80 \%)$.

Further exposure sets compared for three different concentrations of TEA, 20\%, 30\% and 50\% using $20 \mu \mathrm{l}$ of aliquot volumes showed no significant different between the TEA concentrations at the tested environment using ANOVA at $p=0.05$ confidence level for the first exposure set for rainy season, while a significant differrence between the three different concentrations and highly significant different between the sites were observed for the dry season samples exposure (Figure 4).

Preparation solution of $50 \% \mathrm{v} / \mathrm{v}$ TEA in deionized water impedes the absorption of $\mathrm{NO}_{2}$ gas and subsequent conversion to nitrite [29]. The reason for this behavior was associated with TEA basicity. In aqueous solution, TEA acts as a weak base: $\mathrm{pKb}=7.77$ at $25^{\circ} \mathrm{C}$, measured at/ extrapolated to indefinite dilution. There may be insufficient water molecules available in a solution of $50 \%$ $\mathrm{v} / \mathrm{v}$ TEA to achieve equilibrium dissociation. The absorp- 


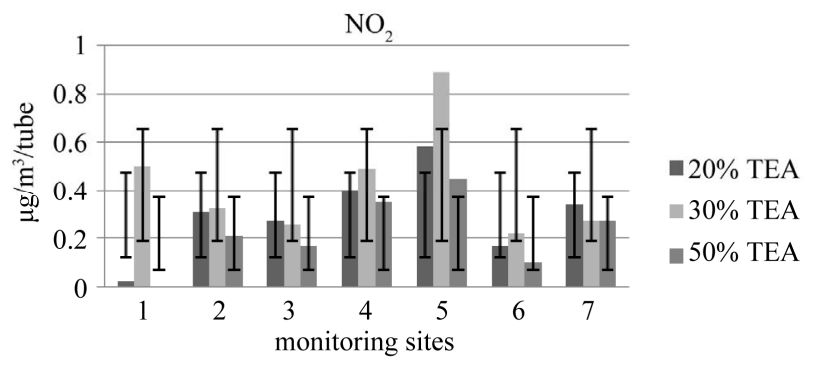

Figure 4. Comparison of absorbent TEA-water concentrations.

tion of the acidic $\mathrm{NO}_{2}$ gas as nitrite may be incomplete if complexation between nitrite ions and TEA is restricted by lack of hydroxyl ions in the solution, resulting lower accumulation of nitrite ion than for other lower concentrated solutions. The hydration of TEA is necessary for conversion of $\mathrm{NO}_{2}$ to nitrite [32]. In the same study the mole ratio of $\mathrm{NO}_{2}$ to TEA for a polluted environment (50 ppb of $\mathrm{NO}_{2}$ ) suggests a presence of very large excess of TEA, 1:1000 for 2 weeks and 1:500 for 4 weeks exposure periods, which favors the current tested result of no significant difference between the $20 \%, 30 \%$ and $50 \%$ TEA v/v absorbents during rainy season and significant different for dry season at $\mathrm{p}=0.05$ and 0.01 level of confidence respectively. It is because the concentrations were higher during dry season.

Sampling medium and absorbent are also very important in tube preparation. The sampling medium, such as filter paper, which is used to soak the absorbent, has a very important role in passive sampling of gases. The selection of filter paper is an important part of passive sampling as it may be the source of contamination and may not be very efficient to use as the sampling medium. In this study, GF filter papers were used after washing with double distilled water. Previous researches had shown that washing filter papers with deionised water could greatly lower the contamination [27]. An investi- gation on the efficiency of filter papers is required to find out the best filter paper for sampling conditions.

\subsection{Comparison with Other Methods}

\subsubsection{Comparison with IVL-Passive Sampler Result}

Result from Test sampler method, IVL-sampler and active-High volume sampler monitoring analysis for both seasons for $\mathrm{NO}_{2}$ concentration were presented in Table 3.

The result also confirmed that site seven was the most polluted among the eight sites studied with $\mathrm{NO}_{2}$ and site eight representing background area the lowest. A linear regression of $\mathrm{NO}_{2}$ measured with the current test passive samplers on the Ferm-IVL passive sampler was reported in Table 4. Strong correlations were obtained for both the seasons, between the current test sampler and FermIVL sampler result (Figures 5 and 6). The result proved reliable ambient $\mathrm{NO}_{2}$ samplers with good precision, quite capable of comparison to the Ferm-IVL sampler.

Accuracy, defined as the percent deviation of $\mathrm{NO}_{2}$ measured by test passive samplers from the Ferm-IVL samplers, was identified as over all under estimation of $18 \%$ for one week exposure and $96 \%$ that for four week exposure for dry season, while it is $68 \%$ for first exposure-Rainy season. In simplest form result showed that test passive samplers under estimate the ambient $\mathrm{NO}_{2}$ than Ferm-IVL samplers. Several factors attributed to this deviation, notably the concentration and amount of absorbent medium, sampler size and the meteorological condition of monitoring period. During dry season, temperature inversion restricts the dispersion of the pollutants resulting elevated concentration in the Kathmandu valley. As a result the one week exposure analysis is sufficient and suitable for ambient $\mathrm{NO}_{2}$ monitoring during dry season. It is further revealed by the weekly variation result analyzed below (Figure 7). Saturations were observed during first week in dry season for $\mathrm{NO}_{2}$. Hence

Table 3. Result from Test sampler method, IVL-sampler and active-high volume sampler monitoring analysis for both seasons for $\mathrm{NO}_{2}$ concentration.

\begin{tabular}{|c|c|c|c|c|c|c|}
\hline \multirow{3}{*}{ Site } & \multicolumn{6}{|c|}{$\mathrm{NO}_{2} \mu \mathrm{g} / \mathrm{m}^{3}$} \\
\hline & \multicolumn{3}{|c|}{ Rainy season } & \multicolumn{3}{|c|}{ Dry season } \\
\hline & Test sampler & Ferm-Badge, IVL & HVS & Test sampler & Ferm-Badge, IVL & HVS \\
\hline 1 & 1.7 & na & 6.6 & 22.7 & na & 22.66 \\
\hline 2 & 1.8 & 12.4 & & 15.98 & 18.9 & \\
\hline 3 & 0.4 & 10.3 & & 10.5 & 15.4 & \\
\hline 4 & 2.7 & 21.7 & & 24.55 & 26.9 & \\
\hline 5 & 15.3 & 18.5 & & 21.08 & 21.0 & \\
\hline 6 & & & & 25.5 & 26.1 & \\
\hline 7 & & & & 52.12 & 52.6 & \\
\hline 8 & & & & 12.3 & 12.8 & \\
\hline
\end{tabular}


Table 4. Comparison of field measurements of test-method with IVL-sampler, to EPA acceptance criteria.

\begin{tabular}{ccccc}
\hline & \multicolumn{3}{c}{$\mathrm{NO}_{2} \mu \mathrm{g} / \mathrm{m}^{3}$} & EPA Acceptance Criteria \\
\cline { 2 - 4 } & Rainy (4 weeks exposure) & Dry (1 weeks exposure) & Dry (4 weeks exposure) & $1 \pm 0.12$ \\
\hline Slope of Regression & 0.510 & 0.941 & 0.136 & -7 to 7 \\
Intercept of Regression & -2.630 & +3.008 & +13.72 & - \\
$\mathrm{R}^{2}$ & 1.66 & 0.985 & 0.104 & 0.946 \\
Pearson Correlation Coefficient, $\mathrm{r}$ & 0.408 & 0.993 & 0.323 & $15 \%$ \\
Precision (rms CV) & 20.7 & 2.015 & 14.97 & $-0.71^{*}$ \\
Significant two sample t-test & 0.04 & 0.05 & & \\
difference, $\mathrm{p}$ value & & &
\end{tabular}

NB: ${ }^{* *}$ Significant difference.

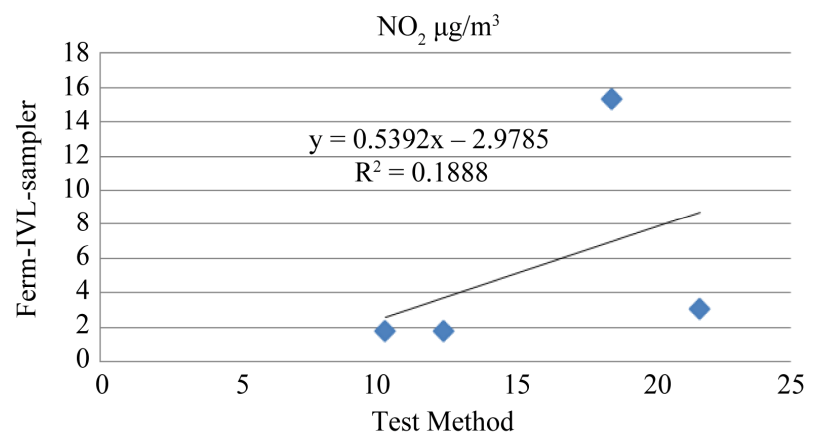

Figure 5. Comparison of $\mathrm{NO}_{2}$ concentration between testmethod with IVL-sampler for rainy season.

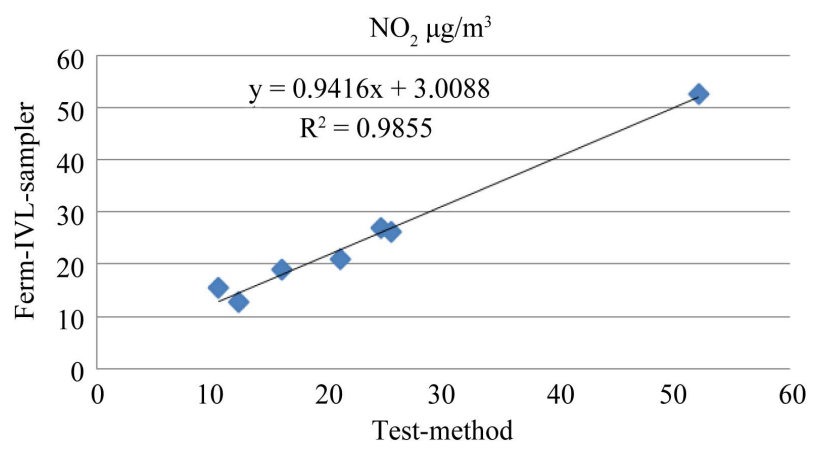

Figure 6. Comparison of $\mathrm{NO}_{2}$ concentration between testmethod with IVL-sampler for dry season.

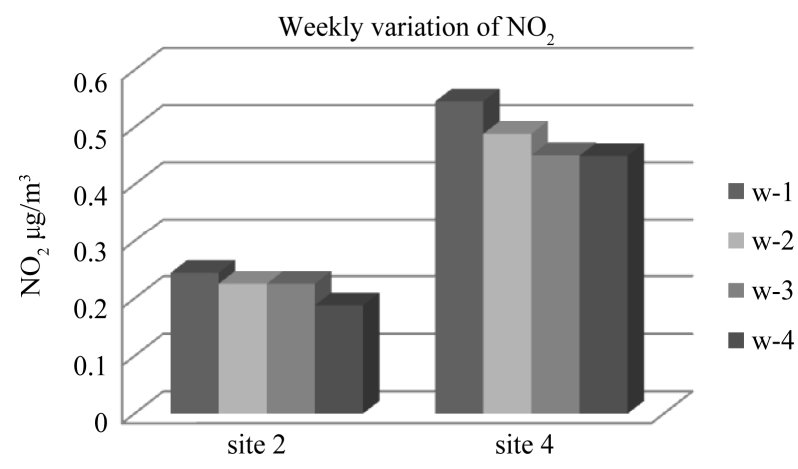

Figure 7. Weekly variation of ambient $\mathrm{NO}_{2}$ sampling per tube for test diffusion tube sampler for March 2008.
Time weighted average made underestimation for four week exposure result. Better result during second exposure analysis (Dry season) in compare to first exposure result attributed to the improvement in the sampler preparation and modifications undertaken.

The fact that $\mathrm{NO}_{2}$ measured with the current test passive samplers correlated extremely well with that measured with the Ferm-IVL samplers further suggests that this bias is systematic. Such systemic bias may be attributed to the assumption made in calculating concentration with the passive samplers, volume and with chemical speciation capability of the absorbing medium. Alternatively, seasonal and/or site correction factors could be developed and applied to adjust passive sampler data [33]. Regression analysis reveals the valid comparison as the parameters, slope, intercept and Pearson correlation coefficient, r; are within the tolerance set by US EPA's acceptance criterion for Environment monitoring (Table 4).

The method comparison further done by Pair t-test (TWO-tailed) to estimate the level of significance of any differences in $\mathrm{NO}_{2}$ measurements by the compared two methods. Sampler means are significantly different if the $\mathrm{p}$ value is $\leq 0.05$ (95\% confidence level), and very highly significantly different if $\mathrm{p} \leq 0.001$ (99.9\% confidence level).

Results showed that for all the exposure analysis, First exposure (rainy) and Second exposure (dry) of $\mathrm{NO}_{2}$ monitoring under tested period are not significantly different except for four week dry season exposure for $\mathrm{NO}_{2}$. It is significantly different at $\mathrm{p} \leq 0.05$ (95\% confidence level).

\subsubsection{Weekly Variation Analysis}

The appropriate duration of exposure period is important in the passive sampling monitoring and analysis of ambient air quality. The combined factors including volume and saturation of absorbent solution, absorbent medium itself, ambient concentration and nature of the pollutant under measurement and local meteorology determined the exposure time in diffusive measurement. Weekly exposure analysis of ambient $\mathrm{NO}_{2}$ carried out at two sites 2 
and 4 up to fourth week period showed in Figure 7.

Two way analysis of variance (ANOVA) for weekly variation of $\mathrm{NO}_{2}$ showed that there were no significant different between the weeks at $p \leq 0.05$ (95\% confidence level). The concentration of $\mathrm{NO}_{2}$ was significantly different between sites at $p \leq 0.05$ (95\% confidence level).

Hence from the ANOVA test and the Figure 7, it is evident that though there was no significant loss of $\mathrm{NO}_{2}$ for four week exposure time, one week is sufficient and suitable for analysis of ambient $\mathrm{NO}_{2}$ for dry season.

\subsubsection{Comparison with High Volume Sampler Measurement}

Monitoring of $\mathrm{NO}_{2}$ using High volume sampler was carried out in site 1 during the period of first and second exposure of Test sampler shows good agreement between two methods for dry season monitoring than those from rainy season (Table 3). The underestimation during rainy season exposure analysis by test method in compare to active high volume sampling method might be due to longer period of exposure of four weeks causing loss of pollutants or some unknown interferences. However, improvement in second sampling result during dry season showed the validity of the test method for the ambient monitoring by developed diffusive samplers in Kathmandu.

\subsection{Detection Limits}

The detection limit of the spectrophotometer obtained from the calibration curve with the help of Equation (5) was $0.09 \mu \mathrm{g} / \mathrm{ml}$ of $\mathrm{NO}_{2}^{-}$The standard deviation of blank values was used to calculate the detection limit for the passive sampling method. The detection limit of $\mathrm{NO}_{2}$ for one week, two weeks, three weeks and four weeks exposure period were estimated to be $2.73 \mu \mathrm{g} / \mathrm{m}^{3}(\mathrm{n}=11)$, $1.77 \mu \mathrm{g} / \mathrm{m}^{3}(\mathrm{n}=11), 1.75 \mu \mathrm{g} / \mathrm{m}^{3}(\mathrm{n}=10)$ and $1.84 \mu \mathrm{g} / \mathrm{m}^{3}$ $(\mathrm{n}=11)$ respectively for developed diffusive samplers.

The detection limits of $\mathrm{NO}_{2}$ for the diffusion tubes were suitable for the study areas as the concentrations measured were not found to be below the detection limit.

\subsection{Conclusions}

The important achievement from this research lies in the possible use of simple polyethylene tubes from local market as diffusive passive sampler for ambient monitoring of selected pollutants with suitable modification in existed methods. It is possible to use these simple kinds of tubes from local market and that can show the trends of $\mathrm{NO}_{2}$ concentrations and work well for passive sampling.

One week exposure period during high pollution statedry season for $\mathrm{NO}_{2}$ is the suitable time period for the ambient sampling and monitoring under the tested/de- veloped experimental condition for Kathmandu. The polyethylene tubes and GF/A filter paper with $20 \mu \mathrm{l}$ of v/v $30 \% \mathrm{TEA} /$ water as absorbent has been used and proven to be good enough for monitoring of $\mathrm{NO}_{2}$.

There was good correlation between measurements of $\mathrm{NO}_{2}$ by developed diffusion tubes in comparison with Ferm-IVL passive samplers from IVL-Sweden. There was no significant different between two methods at $p=$ 0.01 . Though, Test passive samplers under estimate the ambient $\mathrm{NO}_{2}$ than Ferm-IVL samplers. Regression analysis reveals the valid comparison as the parameters, slope, intercept and Pearson correlation coefficient, and $\mathrm{r}$ are within the tolerance set by US EPA's acceptance criterion for Environment monitoring. The comparison of $\mathrm{NO}_{2}$ diffusion tubes and active sampling implied a good agreement. Precision of the passive sampling method for measurement expressed as Coefficient of variation (CV) was found to be consistent with other previous studies. $[4,34]$.

Apparently, there is a need for maintaining and expanding the existing monitoring stations both for monitoring additional air pollutants and current monitoring pollutants, and such an expansion requires large investments and additional operational expenses for a developing country. An urgent action of adopting inexpensive, simple and reliable methods for wide-spread air quality monitoring, simultaneously, at multiple points over large areas is needed for Nepal. Thus, passive sampling is proved to be one such methodology to fulfill this need in applications, as demonstrated by this study for Kathmandu.

Future studies should incorporate towards developing such passive samplings in overcoming the systematic bias observed in the field exposure results due to seasonal and other possible reasons.

\section{Acknowledgements}

The study was supported by grant from National Institute of Science and Technology, Nepal, PhD scholar grant from, Tribhuvan University Nepal. The author acknowledges the other logistic and inspiring support from CEMAT, Water Lab, Nepal, Central Department of Environmental Science, TU, Nepal; Menris-ICIMOD, Nepal; Rapid Urban assessment project funded by UNEP RRCAP, Sida, Stockholm Environment institute (SEI), IVL, Sweden and Ministry of Environment Government of Nepal.

\section{REFERENCES}

[1] F. De Santis, A. Fino, S. Tiwari, C. Vazzana and I. Allegrini, "Development of a Passive Sampling Technique for the Determination of Nitrogen Dioxide and Sulphur Dioxide in Ambient Air," Analytica Chimica Acta, Vol. 346, 
No. 1, 1997, pp. 127-134. doi:10.1016/S0003-2670(97)00075-5

[2] E. D. Palmes, A. F. Gunnison, J. DiMattio and C. Tomczyk, "Personal Sampler for Nitrogen Dioxide," American Industrial Hygiene Association Journal, Vol. 37, No. 10, 1976, pp. 570-577. doi:10.1080/0002889768507522

[3] M. Ferm and P. Svanberg, "Cost-Efficient Techniques for Urban and Background Measurements of $\mathrm{SO}_{2}$ and $\mathrm{NO}_{2}$," Atmospheric Environment, Vol. 32, No. 8, 1998, pp. 13771381. doi:10.1016/S1352-2310(97)00170-2

[4] T. Bush, S. Smith, K. Stevenson and S. Moorcroft, "Validation of Nitrogen Dioxide Diffusion Tube Methodology in the UK," Atmospheric Environment, Vol. 35, No. 2, 2001, pp. 289-296. doi:10.1016/S1352-2310(00)00172-2

[5] M. Ferm, "Principles of Diffusive Monitoring," Measuring Air Pollutants by Diffusive Sampling and Other Low Cost Monitoring Technique Krakow Conference, Krakow, 15-17 September 2009.

http://www.rsc-aamg.org/Pages/Presentations/Krakow200 9.htm

[6] Y. Yanagisawa and H. Nishimura, "A Badge-Type Personal Sampler for Measurement of Personal Exposure to $\mathrm{NO}$ and $\mathrm{NO}_{\mathrm{x}}$ in Ambient Air," Environment International, Vol. 8, No. 1-6, 1982, pp. 235-242. doi:10.1016/0160-4120(82)90033-2

[7] K. Amaya and K. Sugiura, "A Simple, Inexpensive and Reliable Method of Measuring Nitrogen Dioxide Concentration in Ambient Air," Environment Protection Engineering, Vol. 9, 1983, pp. 5-9.

[8] Diffusive Samplers for Nitrogen Dioxide from Gradkoenvironmental, UK. http:// www.gradko.org.uk

[9] D. Krochmal and L. Gorski, "Determination of Nitrogen Dioxide in Ambient Air by Use of a Passive Sampling Technique and Triethanolamine as Absorbent," Environmental Science \& Technology, Vol. 25, No. 3, 1991, pp. 531-535. doi:10.1021/es00015a023

[10] D. Krochmal and L. Gorski, "Modification of AmayaSugiura Passive Sampling Spectrophotometric Method of Nitrogen Dioxide Determination in Ambient Air," Fresenius' Journal of Analytical Chemistry, Vol. 340, No. 4, 1991, pp. 220-222. doi:10.1007/BF00321772

[11] B. C. Cadoff and J. Hodgeson, "Passive Sampler for Ambient Levels of Nitrogen Dioxide," Analytical Chemistry, Vol. 55, No. 13, 1983, pp. 2083-2085. doi:10.1021/ac00263a017

[12] J. D. Mulik, R. G. Lewis and W. A. McCleny, "Modification of a High-Efficiency Passive Sampler to Determine Nitrogen Dioxide or Formaldehyde in Air," Analytical Chemistry, Vol. 61, No. 2, 1989, pp. 187-189. doi:10.1021/ac00177a022

[13] M. Ferm, “A Sensitive Diffusion Sampler," Report, Swedish Environmental Research Institute, Stockholm, 1991.

[14] UNEP/WHO, GEMS/AIR Methodology Reviews Vol. 4: Passive and Active Sampling Methodologies for Measurement of Air Quality, WHO/EOS/94.4.5.UNEP Nairobi, Genava, 1994.

[15] K. Shakey, "Passive sampling of Nitrogen Dioxide and Sulfur Dioxide in Ambient Air," Masters' Thesis, Gradu- ate School, Chiang Mai University, Chiang Mai, 2004.

[16] KVEO, "Kathmandu Valley Environment Outlook", International Centre for Integrated Mountain Development (ICIMOD), Ministry of Environment, Science and Technology (MoEST) and United Nations Environment Programme (UNEP), 2007. www.icimod.org.

[17] B. Sapkota, "Air Pollution Transport from Kathmandu Valley," Journal of the Institute of Engineering, Vol. 3, No. 1, 2004, pp. 30-42.

[18] S. K. Joshi, "Violence against Women in Nepal-Health Care Workers' Role," Kathmandu University Medical Journal, Vol. 1, No. 4, 2003, pp. 231-233.

[19] D. Pudasainee, B. Sapkota, A. Bhatnagar, S. H. Kim and Y. C. Seo, "Influence of Weekdays, Weekends and Bandhas on Surface Ozone in Kathmandu Valley," Atmospheric Research, Vol. 95, No. 2-3, 2010, pp. 150-156. doi:10.1016/j.atmosres.2009.09.007

[20] B. Tuladhar, "Air Quality Management issues and Priorities for Nepal," Technical Paper, National Stakeholder's Meeting, Building Partnership for Clean Air Initiative in Nepal, CANN, Kathmandu, 2008.

[21] MOEST, "Ambient Air Quality of Kathmandu Valley," Report, Ministry of Environment, Science and Technology, Kathmandu, 2006. www.most.gov.np

[22] MOEST, "Ambient Air Quality of Kathmandu Valley," Report, Ministry of Environment, Science and Technology, Kathmandu, 2007. www.most.gov.np

[23] M. Ferm and H. Rodhe, "Measurements of Air Concentrations of $\mathrm{SO}_{2}, \mathrm{NO}_{2}$ and $\mathrm{NH}_{3}$ at Rural and Remote Sites in Asia," Journal of Atmospheric Chemistry, Vol. 27, No. 1, 1997, pp. 17-22. doi:10.1023/A:1005816621522

[24] G. R. Carmichel, M. Ferm, N. Thongboonchoo, J. H. Woo, L. Y. Chan, K. Murano, P. H. Viet, C. Mossberg, R. Bala, J. Boonjawat, P. Upatum, M. Mohan, S. P. Adhikary, A. B. Shrestha, J. J. Pienaar, E. G. Brunke, T. Chen, T. Jie, D. Guoan, L. C. Peng, S. Dhiharto, H. Harhanto, A. M. Jose, W. Kimani, A. Kirouane, J. P. Lacaux, S. Richard, O. Barturen, J. C. Cerda, A. Athayde, T. Tavares, J. S. Cotrina and E. Bilici, "Measurements of Sulfur Dioxide, Ozone and Ammonia Concentrations in Asia, Africa and South Africa Using Passive Samplers," Atmospheric Environment, Vol. 37, No. 9-10, 2003, pp. 1293-1308. doi:10.1016/S1352-2310(02)01009-9

[25] Cornwall Air Quality Forum, Truro $\mathrm{NO}_{2}$ Diffusion Tube Programme, 2000. http://www.cornwall-airquality.org.uk/trurono2.asp

[26] A. Kasper-Giebl and H. Puxbaum, "Deposition of Particulate Matter in Diffusion Tube Samplers for the Determination of $\mathrm{NO}_{2}$ and $\mathrm{SO}_{2}$," Atmospheric Environment, Vol. 33, No. 8, 1999, pp. 1323-1326. doi:10.1016/S1352-2310(98)00298-2

[27] D. Krochmal and A. Kalina," Technical Note: A Method of Nitrogen Dioxide and Sulphur Dioxide Determination in Ambient Air by Use of Passive Samplers and Ion Chromatography," Atmospheric Environment, Vol. 31, No. 20, 1999, pp. 3473-34579. doi:10.1016/S1352-2310(97)00154-4

[28] R. H. Brown, "Monitoring the Ambient Environment 
with Diffusive Samplers: Theory and Practical Considerations," Journal of Environmental Monitoring, Vol. 2, No. 1, 2000, pp. 1-9. doi:10.1039/a906404d

[29] C. Kirby, M. Fox and J. Waterhouse, "Reliability of Nitrogen Dioxide Passive Diffusion Tubes for Ambient Measurement: In Situ Properties of the Triehanolamine Absorbent," Journal of Environmental Monitoring, Vol. 2, No. 4, 2000, pp. 307-312. doi:10.1039/b003124k

[30] D. P. Miller, "Ion Chromatographic Analysis of Palmes Tubes for Nitrite," Atmospheric Environment, Vol. 18, No. 4, 1984, pp. 891-892. doi:10.1016/0004-6981(84)90281-6

[31] S. Seethapathy, T. Gorecki and X. Li, "Review Passive
Sampling in Environmental Analysis," Journal of Chromatography A, Vol. 1184, No. 1-2, 2008, pp. 234-253

[32] E. D. Palmes and E. R. Johnson, "Explanation of Pressure Effects on a Nitrogen Dioxide $\left(\mathrm{NO}_{2}\right)$ Sampler," American Industrial Hygiene Association Journal, Vol. 48, No. 1, 1987, pp. 73-76.

[33] D. K. Ott, "Passive Sampling of Ambient Coarse Particulate Matter, PM10-2.5", Ph.D. Dissertation, Graduate College of the University of Iowa, , 2007.

[34] D. H. F. Atkins, J. Sandalls, D. V. Law, A. M. Hough and K. J. Stevenson, "The Measurement of Nitrogen Dioxide in the Outdoor Environment Using Passive Diffusion Tube Samplers," HMSO, London, 1986. 